\title{
Elevated HPV16 E1 Expression Is Associated with Cervical Cancer Progression
}

\author{
Fern Baedyananda ${ }^{a}$ Arkom Chaiwongkot $^{b}$ Parvapan Bhattarakosol ${ }^{b}$ \\ a Joint PhD Program in Biomedical Sciences and Biotechnology, Department of Microbiology, Faculty of Medicine, \\ Chulalongkorn University, Bangkok, Thailand; ${ }^{b}$ Department of Microbiology, Faculty of Medicine, Chulalongkorn \\ University, Bangkok, Thailand
}

\section{Keywords}

Human papillomavirus · Cervical cancer · Promoter

methylation · HPV E1

\begin{abstract}
Objectives: The primary replication protein, HPV E1, has been shown to play a role in mitigating host defence and disrupting normal cell cycle processes, leading to the development of cancer. This study investigated the expression profile of HPV16 E1 in various stages of cervical cancer development and the factors that control E1 expression. Methods: One hundred and twenty-four HPV16-positive cervical samples ranging from normal to $\mathrm{CIN} 1, \mathrm{CIN} 2 / 3$, and SCC lesions were studied. E1 mRNA expression was determined by ddPCR. Methylation of promoters p97 and p670 was quantified by pyrosequencing, while PCR, $\mathrm{PPCR}$, and sequencing were used to determine the physical state and variations of the HPV16 E1 genome. Results: Increased E1 mRNA expression related to disease progression (normal 0.18, CIN 10.41 , CIN 2/3 0.65, and SCC 0.79) was demonstrated with a significant positive correlation $(r=0.661, p=0.019)$. No association between physical state and E1 expression was found. Methylation of $p 97$ and $p 670$ promoters showed significant eleva-
\end{abstract}

\section{KARGER}

() 2018 S. Karger AG, Basel

E-Mail karger@karger.com

www.karger.com/int tion in SCC compared to normal samples. Only 4.2\% showed genomic variations of HPV16 E1 63-bp duplication. Conclusion: $\mathrm{E} 1$ may play a role in cancer development. The detection of $\mathrm{E} 1 \mathrm{mRNA}$ and promoter methylation may be useful as cancer prognostic markers.

(c) 2018 S. Karger AG, Basel

\section{Background}

Cervical cancer is the second most common gynaecological cancer worldwide [1], with more than $90 \%$ of cases caused by human papillomaviruses (HPV). Although there are over 150 types of HPV, HPV16 is the major etiological agent of cervical cancer and is present in over $50 \%$ of all cervical cancer cases [2]. Different variants of HPV16 result in a distinctive association to disease progression in cervical cancer [3].

All types of HPV, including HPV16, contain early functional proteins and late structural proteins. Of all HPV proteins, only E1 functions as an enzyme, and is responsible for initiating replication of the viral genome inside the host cell. The most prominent promoters for E1 are the early promoter (p97) located in the long control 
region and the differentiation-inducible late promoter (p670) important for the transcription of late genes encoding L1, L2, and E1E4 [4]. The E1 protein is comprised of 4 main domains, the $\mathrm{N}$-terminal domain, the DNA binding domain, the oligomerization domain, and the ATP-dependent helicase domain. In normal conditions, the E1 protein initiates viral replication in conjunction with the E2 protein, the main transcriptional regulator $[5,6]$.

Recent findings have implicated E1 to be a driving factor in carcinogenesis. In a study by Castillo et al. [7], silenced HPV18 E1 in HeLa cells upregulated genes involved in the host immune response and cell cycle regulation, suggesting E1 has some role in carcinogenesis. E1 has also been shown to induce DNA damage, arrest cell growth, and recruit host cell machinery to increase viral replication [8]. Under stress, E1 replicates HPV DNA with low fidelity and the resulting double-stranded breaks, which could be a carcinogenic factor [9].

In this study, we explored the possible role of E1 in cervical cancer development by determining the level of E1 mRNA expression, as well as physical states of the HPV 16 genome in patient cervical samples, ranging from normal, precancerous cervical intraepithelial neoplasia (CIN) 1, CIN 2/3, and squamous cell carcinoma (SCC). We then explored methylation levels in the E1 promoter region as a possible regulator of $\mathrm{E} 1$ expression, and its association with disease progression and the physical state of the viral genome. Lastly, we determined the importance of genetic variations in the $\mathrm{E} 1$ gene by exploring a variant of HPV16 E1.

\section{Materials and Methods}

\section{Clinical Specimens and HPV DNA Detection}

Cervical samples in the SurePath ${ }^{\mathrm{TM}}$ liquid-based cytology system were obtained from routine Pap smears at the Gynaecological Outpatient Department, King Chulalongkorn Memorial Hospital, Bangkok, Thailand. The samples were collected from 2012 to 2014, and stored at $-80^{\circ} \mathrm{C}$. The presence of HPV 16, 18, and high-risk HPV DNA was detected in all samples at the Virology Unit, Department of Microbiology, King Chulalongkorn Memorial Hospital, Bangkok, Thailand, by using either the CLART ${ }^{\circledR}$ HPV2 system (Genomica, Spain) or the Cobas ${ }^{\circledR} 4800$ high-risk HPV test (Roche, USA). The CLART ${ }^{\circledR}$ HPV2 is a microarray system that detects and distinguishes 35 HPV types (HPV6, 11, 16, 18, 26, 31, 33, 35, 39, $40,42-45,51-54,56,58,59,61,62,66,68,70-73,81-85$, and 89). Briefly, HPV DNA was extracted manually from $1 \mathrm{~mL}$ of cervical sample using the High Pure Viral Nucleic Acid Kit (Roche, Germany). Extracted nucleic acid was amplified and hybridized to HPV type-specific probes following the protocol of the manufacturer. The results were visualized and interpreted by the Clinical
Arrays Reader (Genomica). The Cobas ${ }^{\circledR} 4800$ high-risk HPV is a fully automated system including sample preparation, real-time polymerase chain reaction (PCR) amplification, and nucleic acid hybridization for the detection of 14 high-risk HPV types, i.e., HPV16, HPV18, and 12 other high-risk HPV types (HPV31, 33, $35,39,45,51,52,56,58,59,66$, and 68 , as a pooled result) in a single analysis.

Only leftover HPV16-positive specimens were used in this study. The use of leftover specimens was approved by the Institutional Review Board, Faculty of Medicine, Chulalongkorn University, which is a WHO-certified ethics committee (COA No. 482/2015, IRB No. 298/58).

A total of 124 HPV16-positive samples were selected for this study. Pap smear results, i.e., normal, low/high-grade squamous intraepithelial lesion (LSIL/HSIL), and SCC and histological results from colposcopy (CIN 1, CIN 2/3, and SCC) were also obtained.

\section{Cell Culture}

HPV16 DNA-positive cell lines, CaSki (more than 600 copies) and $\mathrm{SiHa}$ (1-2 copies) were grown in Eagle's Minimum Essential Medium (Gibco, USA) supplemented with $10 \%$ foetal bovine serum (Gibco, USA), 100 unit $/ \mathrm{mL}$ penicillin, $100 \mu \mathrm{g} / \mathrm{mL}$ streptomycin (Bio Basic Inc., Canada), and 0.01 M N-2-hydroxyethylpiperazine-N-2-ethane sulfonic acid (HEPES; Sigma Aldrich, USA).

\section{HPV16 E1 mRNA Detection by Droplet Digital PCR}

Total cellular RNA was extracted from cervical samples using the AllPrep DNA/RNA Mini Kit (Qiagen, Germany) and reverse transcribed by Superscript IV (Thermo Fisher Scientific, USA), following the manufacturers' protocols. E1 cDNA was amplified using the E1 primers [10] (Integrated DNA Technologies, Singapore), and quantitated by ddPCR (droplet digital PCR; Bio-Rad, USA) using a FAM-labelled TaqMan MGB probe (Thermo Fisher Scientific). $\beta$-Actin mRNA levels were determined using a primer assay kit (catalogue No. Hs99999903_m1; Thermo Fisher Scientific). All of the primer sequences and probes are presented in Table 1 .

ddPCR reactions were performed according to the manufacturer's instructions using a C1000 Touch ${ }^{\mathrm{TM}}$ Thermal Cycler (BioRad). Results were analysed by QuantaSoft software (Bio-Rad). Only droplets above the minimum amplitude threshold level determined by negative controls were considered. The amount of HPV16 E1 mRNA was normalized to $\beta$-actin mRNA levels for each individual sample.

\section{HPV16 Physical State Detection}

PCR was used to determine the physical state of the HPV16 genome by detecting the $\mathrm{E} 2$ region, which is deleted upon integration using primers specific to that region (Integrated DNA Technologies). PCR conditions were performed according to Peitsaro et al [11]. For each reaction, 10-50 ng of the template DNA were used. The amplified product of $82 \mathrm{bp}$ (pure episomal/mixed form) or absence of a detectable PCR product (integrated form) were determined by $2 \%$ agarose gel electrophoresis.

In order to differentiate the physical state of the HPV16 genome into pure episomal, mixed, and integrated forms, quantitative real-time PCR (qPCR) detecting both E2 and E6 genes was performed using the StepOnePlus Real-Time PCR System (Applied Biosystems, USA). External standard curves were deter- 
Table 1. Primers and probes

\begin{tabular}{|c|c|c|c|c|}
\hline Gene & Sequence & & Size, bp & Reference \\
\hline E1 & $\begin{array}{l}\text { Forward: } \\
\text { Reverse: } \\
\text { TaqMan MGB probe: }\end{array}$ & $\begin{array}{l}\text { 5'-GCGGGTATGGCAATACTGAA-3' } \\
\text { 5'-TAACACCCTCTCCCCCACTT-3' } \\
\text { 5'-CCATGTAGTCAGTATAGTGG-3' FAM }\end{array}$ & $210 / 146$ & $\begin{array}{l}\text { Bogovac [10], } 2011 \\
\text { This study }\end{array}$ \\
\hline E2 & $\begin{array}{l}\text { Forward: } \\
\text { Reverse: }\end{array}$ & $\begin{array}{l}\text { 5'-ACGAAGTATCCTCTCCTGAAATTATTAG-3' } \\
\text { 5'-CCAAGGCGACGGCTTTG-3' }\end{array}$ & 82 & Peitsaro [11], 2002 \\
\hline p97 & $\begin{array}{l}\text { Forward: } \\
\text { Reverse: } \\
\text { Sequencing primer: }\end{array}$ & $\begin{array}{l}\text { 5'-TTGTAAAATTGTATATGGGTGTG-3' } \\
\text { Biotin-5'-AAATCCTAAAACATTA CAATTCTC-3' } \\
\text { 5'-AATTTATGTATAAAATTAAGGG-3' }\end{array}$ & 192 & Rajeevan [13], 2006 \\
\hline p670 & $\begin{array}{l}\text { Forward: } \\
\text { Reverse: } \\
\text { Sequencing primer: }\end{array}$ & $\begin{array}{l}\text { 5'-TGGAATAATATTAGAATAGTAATATAATAAA-3' } \\
\text { Biotin-5'-TTATCCAACTAAACCATCTATTTCATCC-3' } \\
\text { 5'-GTAAAGATTTTATAATATAAGGGG-3' }\end{array}$ & 339 & This study \\
\hline
\end{tabular}

mined for both the E6 and E2 genes using the full-length HPV16 plasmid, p1203 PML2d HPV16, a gift from Peter Howley (Addgene plasmid No. 10869). Serial 10-fold dilutions containing $10^{7}-$ $10^{3}$ copies were amplified using the primers in Table 1 . In order to mimic mixed forms of the HPV16 genome, full-length HPV16 plasmid was mixed with $\mathrm{SiHa}$ DNA to create mixed forms with $20-80 \%$ integration [12]. The PCR reactions of E6 and E2 were run simultaneously in separate tubes under the same conditions, as follows: $1 \times$ SsoAdvanced ${ }^{\mathrm{TM}}$ Universal SYBR ${ }^{\circledR}$ Green Supermix, 400 nM forward and reverse primers, and 10-50 ng of template DNA. The PCR conditions were: initial denaturation at $95^{\circ} \mathrm{C}$ for $30 \mathrm{~s}$, followed by 40 cycles of $95^{\circ} \mathrm{C}$ for $10 \mathrm{~s}$, and $60^{\circ} \mathrm{C}$ for $1 \mathrm{~min}$. The ratio of $\mathrm{E} 2 / \mathrm{E} 6$ copies was determined in each sample.

HPV16 Methylation of Early ( $p 97)$ and Late (p670) Promoters by Pyrosequencing

DNA extracted from patient samples $(1 \mu \mathrm{g})$ was bisulphitetreated following the protocol of the EZ DNA-Gold Bisulphite Conversion Kit (Zymo Research, USA) and used to determine the methylation status of both the early (p97) and the late (p670) promoters. In brief, bisulphite-modified DNA was amplified by PCR using primers specific to p97 [13] and p670 (Integrated DNA Technologies). The PCR conditions were: initial denaturation at $95^{\circ} \mathrm{C}$ for $10 \mathrm{~min}$, followed by 50 cycles of $95^{\circ} \mathrm{C}$ for $1 \mathrm{~min}, 55^{\circ} \mathrm{C}$ for $1 \mathrm{~min}$, and $72^{\circ} \mathrm{C}$ for $1 \mathrm{~min}$, and a final extension at $72^{\circ} \mathrm{C}$ for $10 \mathrm{~min}$. The amplified products were then pyrosequenced with sequencing primers for p97 and p670 using the Pyromark q96 (Qiagen).

\section{HPV16 E1 63-bp Duplication}

The 63-bp duplication studies were carried out by PCR amplification using E1 primers (Table 1). For each reaction, 10-50 ng of the template DNA was mixed with $1 \times$ PCR buffer, $3 \mathrm{~mm}$ $\mathrm{MgCl}_{2}, 200 \mu \mathrm{M} \mathrm{dNTP}, 400 \mu \mathrm{M}$ of each primer, and 1.25 U Taq DNA Polymerase (Thermo Fisher). The PCR conditions were: initial denaturation at $95^{\circ} \mathrm{C}$ for $5 \mathrm{~min}$, followed by 40 cycles of $94^{\circ} \mathrm{C}$ for $30 \mathrm{~s}, 55^{\circ} \mathrm{C}$ for $30 \mathrm{~s}$, and $72^{\circ} \mathrm{C}$ for $1 \mathrm{~min}$, with a final ex- tension at $72^{\circ} \mathrm{C}$ for $10 \mathrm{~min}$. The PCR products were detected by $2 \%$ agarose gel electrophoresis, excised from agarose gels, purified using a NucleoSpin PCR Cleanup and Gel Extraction kit (Macherey-Nagel, Germany), and sent for sequencing (AIT Biotech, Singapore).

\section{Statistical Analysis}

The statistical analysis was performed using GraphPad Prism 6 software. One-way ANOVA was used to analyse the physical state. Student $t$ and Mann-Whitney tests were used to determine the differences in E1 expression and methylation. Data are expressed as the mean, standard deviation (SD), and/or standard error (SE). Statistically significant differences were determined at $p<0.05$.

\section{Results}

\section{Patient Demography}

One-hundred and twenty-four HPV16-positive samples were used in this study. The samples were categorized using cytology (Pap smear) and histology (colposcopy) results. The normal cytology HPV16-positive samples were recruited as our "normal" group. Colposcopy was performed in all patients with abnormal Pap smear results. The Pap smear results perfectly correlated with the colposcopy results, i.e., $\mathrm{LSIL}=\mathrm{CIN} 1, \mathrm{HSIL}=\mathrm{CIN} 2 / 3$, and SCC. From this information, this study presents 124 categorized samples as: normal $(n=22)$, CIN $1(n=38)$, CIN 2/3 $(n=27)$, and SCC $(n=37)$. The mean age (years) $\pm \mathrm{SD}$ (range) for each group were normal, $44.35 \pm 8.03$ (29-55); CIN I, $44.35 \pm 12.50$ (16-56); CIN 2/3, $39.37 \pm$ 10.43 (21-57), and SCC, $51.45 \pm 14.89$ (28-78). 
Fig. 1. E1 mRNA expression increases with the progression of cervical carcinoma. Total cellular RNA was extracted from cervical samples and reverse transcribed. $\mathrm{Pa}$ tient cDNA was used for ddPCR. a E1 expression was determined relative to the clinical stage of each patient and shown to increase significantly with disease progression. b The physical state of the viral genome (episomal, mixed, or integrated) was determined by qPCR, and E1 expression was compared to the viral genome physical state. Data are presented as the ratio between E1 mRNA and $\beta$-actin. Bars represent the standard error. The $p$ values of statistical significance are indicated.

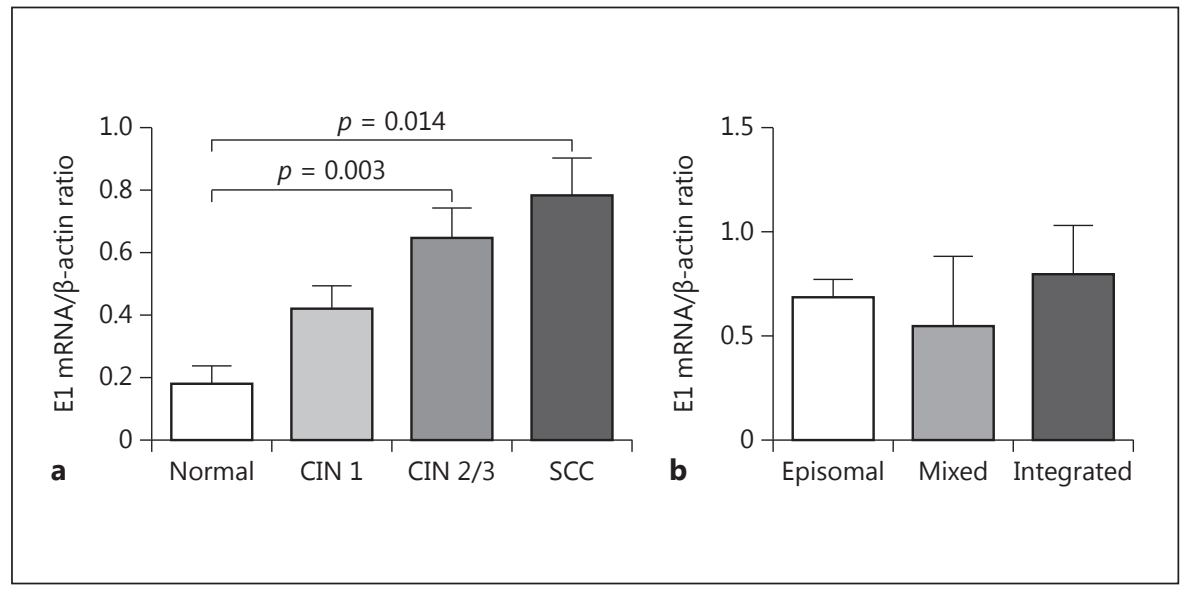

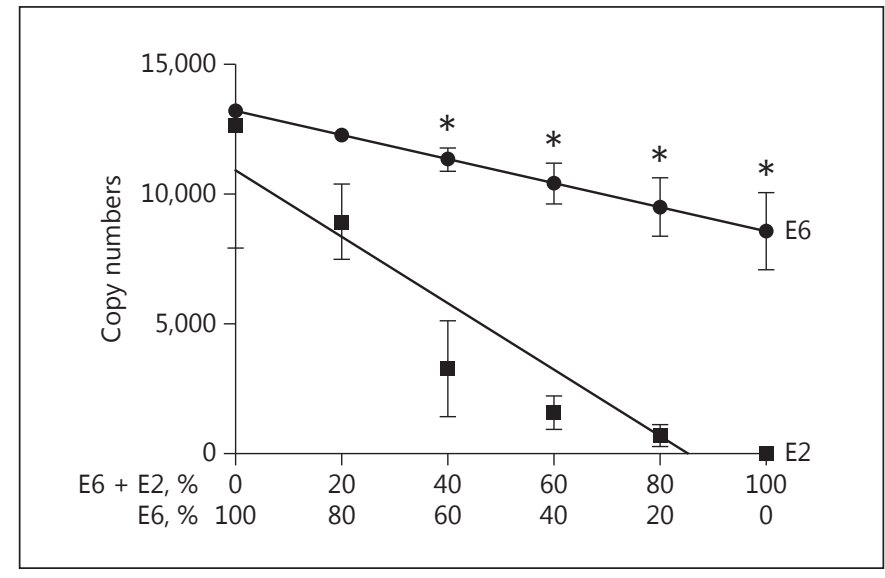

Fig. 2. Establishment of a cut-off value for episomal and mixed forms using HPV16 E2 and E6 genes. Full-length HPV16 plasmid DNA was mixed with $\mathrm{SiHa}$ DNA to produce mixed forms of HPV16 episomal and integrated DNA. These forms represented episomal, integrated, and mixed forms ranging from 20 to $80 \%$ integration. Differences in E2 and E6 copy numbers were determined by unpaired $t$ test. Bars indicate standard error; ${ }^{*} p<0.05$.

\section{E1 mRNA Expression Increases with Disease Progression}

It has been established that $\mathrm{E} 1$ is essential to the initiation of viral replication and could potentially instigate carcinogenesis [7]; consequently, we first sought to investigate the correlation between E1 expression and carcinogenesis. E1 mRNA expression was quantitatively determined and normalized to $\beta$-actin for each sample. Among 39 samples, the mean relative E1 mRNA expression \pm SE (range) were: normal $(n=5), 0.18 \pm 0.06(0.01-0.33)$; CIN $1(n=9), 0.42 \pm 0.07(0.11-0.70)$; CIN 2/3 $(n=7)$, $0.65 \pm 0.10(0.29-1.10)$, and SCC $(n=18), 0.79 \pm 0.12$
(0.04-1.60; Fig. 1a). Relative E1 mRNA expression in CaSki and SiHa cervical cancer cell lines were 0.13 and 0.06 , respectively. To determine if $\mathrm{E} 1$ expression was consistent throughout all clinical stages, the mean E1 mRNA level of all samples (0.60) was set as a cut-off point. Our results revealed that the percentage of samples with E1 mRNA expression above the cut-off point were $0.0 \%$ (normal), $25.0 \%$ (CIN 1), 71.4\% (CIN 2/3), and 58.8\% (SCC), indicating that $\mathrm{E} 1 \mathrm{mRNA}$ expression increased in relation to the disease stage. A significant increase in E1 expression in correlation with disease progression between SCC samples and normal samples $(p=0.014)$ and CIN $2 / 3$ and normal samples ( $p=0.003$ ) was found (Fig. 1a). A significant positive correlation between E1 expression and the clinical stage was demonstrated $(r=0.661, p=0.019)$.

\section{E1 Expression Is Not Related to HPV16 Physical State}

The ability of HPV to cause cancer has been previously correlated with the physical state of the viral genome, categorized into pure episomal, integrated, and mixed forms $[14,15]$. Viral genome integration often results in the disruption of the $\mathrm{E} 2$ gene, which leads to overexpression of the viral oncogenes E6 and E7 [16], significantly increasing the pathogenicity of HPV due to the function of these known oncoproteins [17-19]. In contrast to the HPV 18 viral genome, which has been previously shown to be completely integrated in more than $90 \%$ of cancer cases, HPV16 integration was found in early neoplasia while, in contrast, the episomal form was present in SCC cases. Thus, the physical state of the HPV16 genome related to cancer development remains unclear.

We previously indicated that E1 expression correlated with disease progression (Fig. 1a); therefore, we questioned if the expression of E1 was influenced by the phys- 


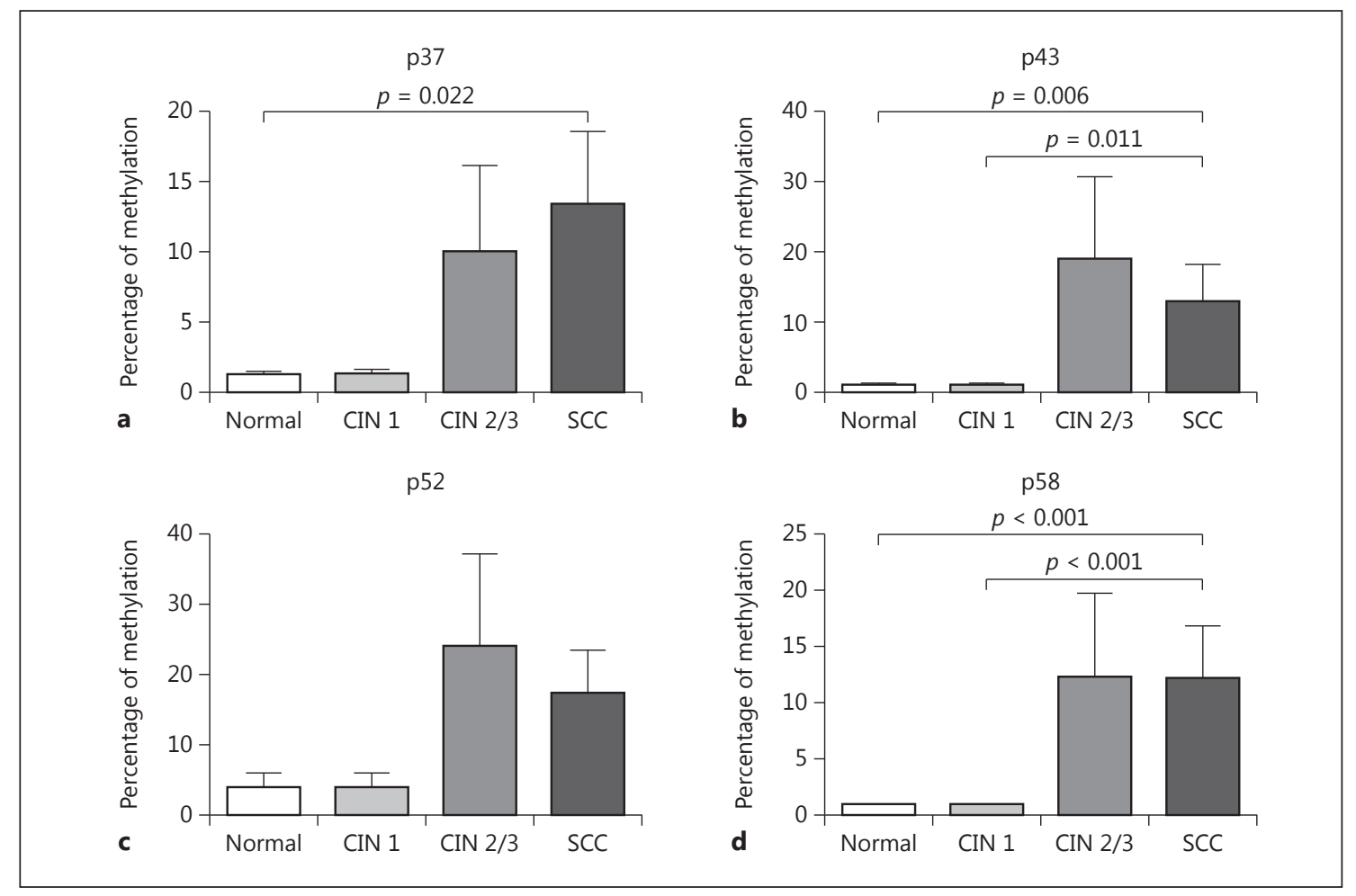

Fig. 3. Significant difference in methylation between cancer and normal patients was observed at 3 positions in the E2BS: p37, p43, and p58. DNA extracted from patient samples was treated with bisulphite and methylation was quantitated by pyrosequencing. The percentages of methylation at different CpG positions in the E2BS were then analysed in comparison to the clinical stage of each patient sample. Data are represented as the mean of methylation percentage: p37 (a), p43 (b), p52 (c), and p58 (d).

Table 2. Physical state determined by PCR and qPCR

\begin{tabular}{llllllr}
\hline Method & Physical state & Normal & CIN 1 & CIN 2/3 & SCC & Total \\
\hline PCR & Mixed & $3(50)$ & $7(88)$ & $6(100)$ & $13(68)$ & $29(74)$ \\
& Integrated & $3(50)$ & $1(12)$ & $0(0)$ & $6(32)$ & $10(26)$ \\
\hline qPCR & Episomal & $2(33)$ & $7(88)$ & $5(83)$ & $7(37)$ & $21(54)$ \\
& Mixed & $2(33)$ & $1(12)$ & $1(17)$ & $7(37)$ & $11(28)$ \\
& Integrated & $2(33)$ & $0(0)$ & $0(0)$ & $5(26)$ & $7(18)$ \\
\hline Discordance, $n$ & & 1 & 1 & 0 & 1 & \\
\hline
\end{tabular}

Values in parentheses are percentages.

ical state of the viral genome. In this experiment, we determined the viral genome status by amplifying the region of $\mathrm{E} 2$ that is deleted upon viral integration into the host genome by PCR, and 111 out of 124 samples (89.5\%) from different clinical stages were successfully amplified. Of these, integration of the viral genome was observed in 31 samples (28\%), i.e., normal, 7/19 (37\%); CIN 1, 10/34
(29\%); CIN2/3, 6/24 (25\%), and SCC, 8/34 (24\%), whereas the rest $(72 \%)$ exhibited a mixed or pure episomal form. To distinguish the episomal from mixed form, we performed qPCR in 39 samples. Standard curves for both E2 and E6 were constructed using full-length HPV16 plasmids, and the $r^{2}$ values were 0.98 and 0.983 . To set a cut-off point between mixed and episomal forms, full- 
Table 3. Methylation percentage at each position of HPV16 early and late promoters

\begin{tabular}{|c|c|c|c|c|}
\hline \multirow[t]{2}{*}{ Group } & \multicolumn{4}{|c|}{$\%$ methylation } \\
\hline & normal & CIN 1 & CIN 2/3 & SCC \\
\hline \multicolumn{5}{|c|}{ Early promoter ( $p 97)$} \\
\hline \multicolumn{5}{|c|}{ CpG 37} \\
\hline Mean & 1.300 & 1.375 & 10.08 & 13.43 \\
\hline SE & 0.21 & 0.26 & 6.088 & 5.14 \\
\hline Range & $1-3$ & $1-3$ & $1-60$ & $1-55$ \\
\hline \multicolumn{5}{|l|}{ CpG $42^{\circ}$} \\
\hline Mean & 1.11 & 1.13 & 19.00 & 13.07 \\
\hline SE & 0.11 & 0.13 & 11.65 & 5.16 \\
\hline Range & $1-2$ & $1-2$ & $1-68$ & $1-55$ \\
\hline \multicolumn{5}{|l|}{ CpG 52} \\
\hline Mean & 4.00 & 4.00 & 24.17 & 17.45 \\
\hline SE & 2.00 & 2.00 & 12.96 & 6.10 \\
\hline Range & $2-8$ & $2-8$ & $2-66$ & $2-55$ \\
\hline \multicolumn{5}{|l|}{ CpG 58} \\
\hline Mean & 1.00 & 1.00 & 12.36 & 12.29 \\
\hline SE & 0.00 & 0.00 & 7.42 & 4.54 \\
\hline Range & $1-1$ & $1-1$ & $1-66$ & $1-53$ \\
\hline Mean total & 1.29 & 1.37 & 12.60 & 12.96 \\
\hline \multicolumn{5}{|c|}{ Late promoter (p670) } \\
\hline \multicolumn{5}{|c|}{$\mathrm{CpG} 497$} \\
\hline Mean & 21.00 & 29.00 & 21.20 & 45.50 \\
\hline SE & 2.52 & 4.16 & 2.34 & 7.50 \\
\hline Range & $16-24$ & $20-39$ & $14-28$ & $38-53$ \\
\hline \multicolumn{5}{|l|}{ CpG 504} \\
\hline Mean & 46.67 & 61.80 & 46.75 & 62.50 \\
\hline SE & 9.97 & 8.89 & 4.70 & 1.5 \\
\hline Range & $31-57$ & $42-85$ & $35-58$ & $61-64$ \\
\hline \multicolumn{5}{|l|}{ CpG 507} \\
\hline Mean & 25.00 & 34.80 & 19.80 & 44.00 \\
\hline SE & 5.51 & 5.03 & 2.56 & 5.00 \\
\hline Range & $14-31$ & $22-47$ & $13-28$ & $39-49$ \\
\hline \multicolumn{5}{|l|}{ CpG 539} \\
\hline Mean & 38.50 & 37.20 & 36.00 & 46.00 \\
\hline SE & 1.50 & 5.57 & 6.43 & 2.00 \\
\hline Range & $37-40$ & $23-51$ & $26-48$ & $44-48$ \\
\hline Mean total & 32.27 & 40.70 & 29.41 & 49.50 \\
\hline
\end{tabular}

length plasmid DNA was mixed with $20-80 \%$ SiHa DNA (absence of the E2 gene), and the significant difference between mean copies of E2 and E6 was set as the cut-off point of 0.6 (Fig. 2). Of the 39 samples, integrated, mixed, and episomal forms were observed in 18,28 , and $54 \%$, respectively (Table 2). According to the qPCR results, the episomal form was observed in $33 \%$ of normal, $88 \%$ of CIN $1,83 \%$ of CIN $2 / 3$, and $37 \%$ of SCC patients. Three discrepancies (integrated to the mixed form) were found.

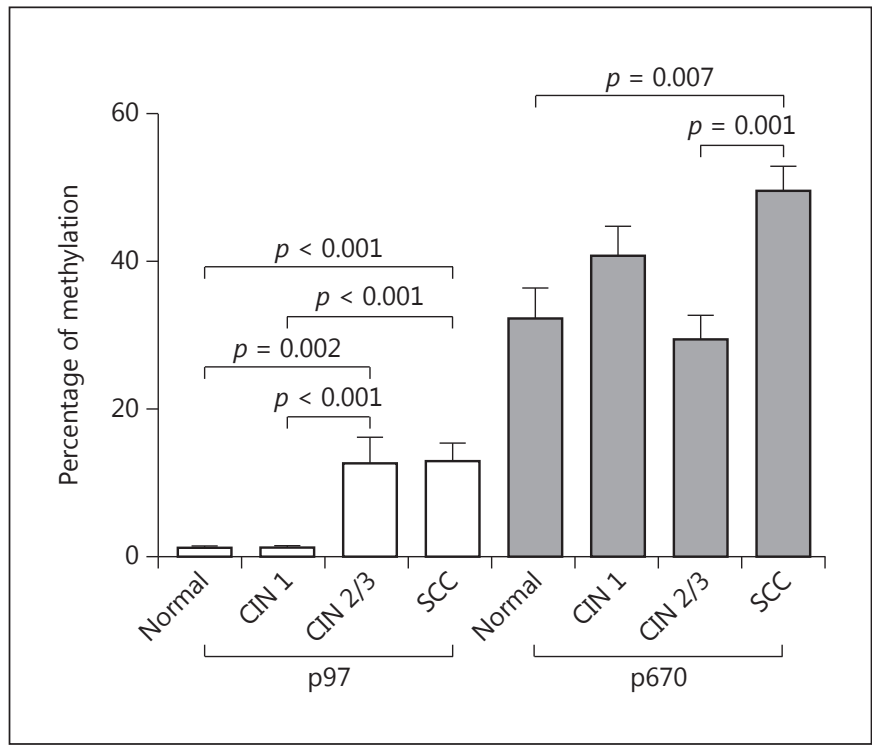

Fig. 4. Methylation of all positions of E2BS shows a significant difference between SCC/CIN 2/3 patients and normal/CIN 1 patients. Late promoter methylation (p670) is consistently higher than E2BS methylation for all clinical stages. In the p670 region, SCC patients exhibited significantly higher methylation than normal patients.

Our results convinced us that the HPV16 genome prefers to maintain the episomal form in either the mixed or pure form, rather than having a purely integrated genome. E1 mRNA expression was then compared to the physical state of the HPV16 genome determined by both PCR and qPCR. For PCR, no significant difference between the E1 expression (mean \pm SE) $0.73 \pm 0.20$ for integrated HPV and $0.65 \pm 0.08$ for the mixed/pure episomal form was found $(p=0.76)$. Similarly, qPCR showed no difference $(p=0.487)$ among episomal $(0.97 \pm 0.25)$, mixed $(0.30 \pm 0.15)$, and integrated $(0.74 \pm 0.19)$ forms (Fig. 1b). Our results indicate that the physical state may not be a crucial factor in regulating E1 expression or there are more underlying factors that are correlated to the dynamic integration pattern of HPV16.

\section{Methylation of E2BS Is Associated with SCC}

Gene expression is regulated by many different mechanisms, one of which is DNA methylation. Since E1 is controlled by both the early and late promoters, we explored methylation in both promoter regions. We specifically focused on the E2BS (E2 binding sites) responsible for transcriptional repression (nucleotide positions $37,43,52$, and 58), in the early promoter region (p97) where the E2 protein binds resulting in negative regula- 


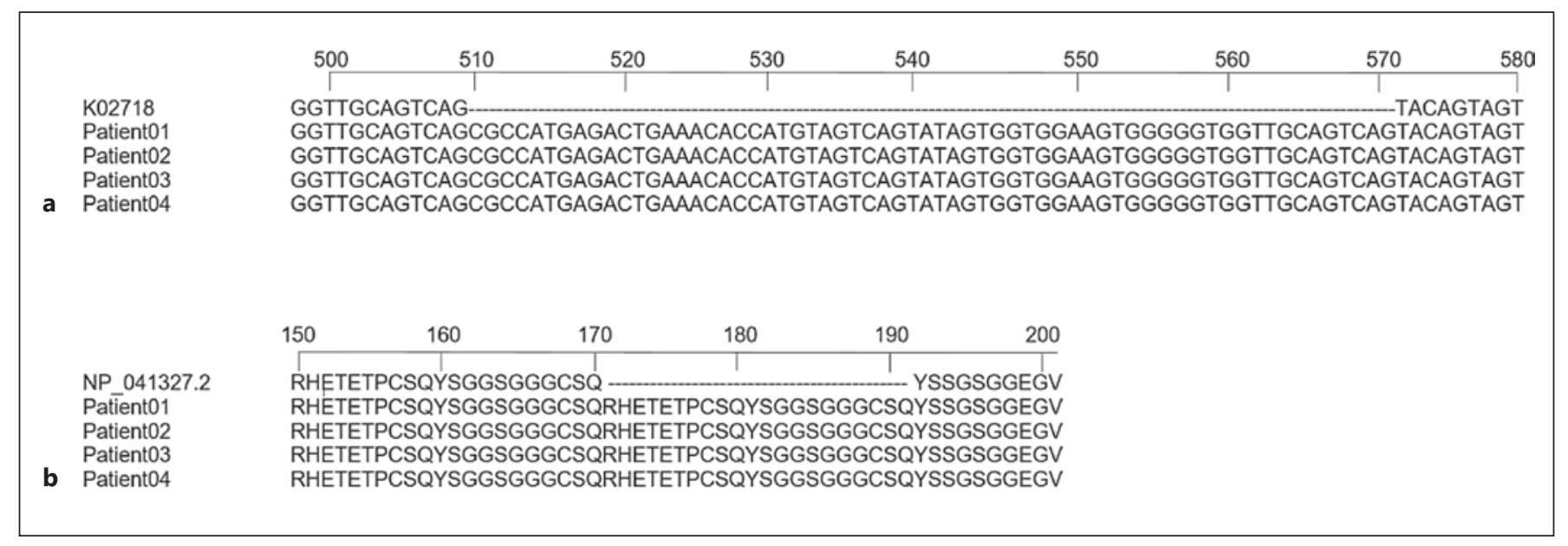

Fig. 5. A 63-bp duplication was found in the E1 region in 4 clinical samples. Samples containing the 63-bp duplication in the E1 region are shown. a The nucleotide sequence compared to reference sequence K02718. b The amino acid sequence compared to reference sequence NP_041327.2.

tion of viral gene expression. Sixty-six samples (20 normal, 13 CIN 1, 14 CIN 2/3, and 19 SCC) were recruited; the methylation percentage of each position is shown in Table 3. Interestingly, mean methylation levels of all 4 positions in the E2BS were higher in CIN 2/3 (12.60\%) and SCC (12.96\%) patients than in normal (1.29\%) and CIN 1 (1.37\%) patients (Table 3$)$. The methylation status in SCC samples was significantly higher compared to normal samples, for positions $37(p=0.022), 43(p=$ $0.006)$, and 58 ( $p<0.001$; Fig. 3a, b, d). In addition, SCC samples could also be differentiated at a significant level, from CIN 1 patients at positions $43(p=0.011)$ and 58 $(p<0.001$; Fig. 3b, d). E2BS methylation in SCC and CIN $2 / 3$ samples was significantly higher compared with normal ( $p<0.001$ and 0.002 , respectively) and CIN 1 ( $p<$ 0.001 and $<0.001$, respectively; Fig. 4).

We also explored the differentiation-induced late promoter region (p670) at nucleotide positions 497, 504, 507 , and 539. Thirty samples ( 12 normal, 9 CIN 1, 5 CIN $2 / 3$, and 4 SCC) were investigated. The methylation levels of p670 were higher than those of E2BS in all stages (Fig. 4). For methylation at each position in the p670 region (497, 504, 507, and 539), no significant differences were noted. However, statistically significant methylation of p670 in SCC was indicated compared to normal $(p=0.007)$ and CIN 2/3 $(p=0.001)$, except CIN $1(p=$ 0.2; Fig. 4). Interestingly, CaSki and $\mathrm{SiHa}$ cells showed different patterns of methylation. CaSki cells exhibited hypermethylation at all early and late promoter positions with a range of $56-82 \%$, whereas $\mathrm{SiHa}$ cells exhibited hy- pomethylation with a range of $0-2 \%$. Nevertheless, E1 expression from both cell lines was comparable ( 0.13 and 0.06 , respectively).

\section{Additional Genetic Events That May Be Involved in E1-Associated Carcinogenesis}

In addition to $\mathrm{E} 1$ expression levels, genetic variation in the E1 gene was explored to determine a possible correlation between genetic variance and disease progression. It has been previously reported that a 63-bp duplication in the E1 gene of HPV16 is associated with lower disease progression [20]. Therefore, the prevalence of the 63-bp duplication genomic variant of HPV16 E1 in our HPV16positive samples was studied. Ninety-five out of 124 samples (15 normal, 22 CIN 1, 32 CIN 2/3, and 26 SCC) were successfully analysed. The 63-bp duplication was exhibited in 4 samples (4.2\%), all of which were categorized as CIN. Nucleotide and amino acid sequences of those 4 samples were analysed using reference HPV 16 sequences K02718 and NP_041327.2 (Fig. 5).

\section{Discussion}

The major cause of cervical cancer is persistent HPV infection, although a minor population $(<1 \%)$ of HPVnegative cancer has been reported [21,22]. HPV16 causes the majority of all cervical cancer cases [23]. The most extensively studied mechanism of HPV carcinogenesis involves the overexpression of known oncoproteins, E6 
and E7. These oncoproteins have been demonstrated to contribute towards malignant transformation by mainly targeting p53 and pRb tumour suppressor proteins [17, $24]$. Recent studies have indicated that other proteins of HPV may also work in conjunction with E6 and E7 to drive the transformation of host cells [25].

E1 is a helicase and the only enzyme encoded by HPV [26]. It can interact with host DNA replication machinery [27-29], induce DNA damage, and mitigate host defence $[7,30]$. Interestingly, functions ranging from cell cycle arrest and proliferation inhibition to the induction of DNA damage have been attributed to E1, independent of the E6 and $\mathrm{E} 7$ proteins $[8,30]$. It is likely that $\mathrm{E} 1$ has a role in regulating the host cell cycle. To better understand the role of E1 in cervical carcinogenesis, we analysed the expression pattern of $\mathrm{E} 1$ by first determining the expression level of E1 in HPV16-positive samples. HPV16 E1 mRNA was used to determine expression instead of E1 protein detection due to the absence of a good commercial E1 antibody. Our results revealed that E1 mRNA expression significantly increased with disease severity (Fig. 1a). Our findings are similar to a previous study by Schmitt et al. [31] who demonstrated that the levels of E1 mRNA in LSIL patients were lower than those in HSIL and cancer patients. Expression of mRNA might correlate with the copy number of HPV16 genome in the cells. However, CaSki cells (600 copies/cell) and SiHa cells (1-2 copies/ cell) had almost the same amount of E1 mRNA expression, 0.13 and 0.06 , respectively. Thus, there is no correlation between E1 mRNA expression and the copies of the HPV16 genome. A similar observation by Wang-Johanning et al. [32] also demonstrated that the expression of E6 and E7 mRNA in CaSki and SiHa cells are nearly identical, indicating that mRNA expression is governed by factors other than viral copy numbers. We then further explored additional mechanisms that could account for E1 transcriptional activity.

The physical state of the HPV genome has always been believed to be an integral part in disease progression. This holds true for HPV 18, in which $98-100 \%$ of all cancer cases show complete integration of the viral genome in carcinoma. However, it has been demonstrated in numerous studies that HPV16 shows a different integration pattern in conjunction with disease. Zhang et al. [33] found a $27.7 \%$ integration rate of HPV 16 in precancerous lesions. This study detected a high number of samples with fully integrated HPV16 in normal samples $(2 / 6$, $33 \%)$, similar to a finding reported by Dutta et al. [34] (27\% integration in normal samples). However, no full integration was found in precancerous stages (CIN 1-3) and only $26.32 \%$ in SCC (Table 2). Although early integration was present, the majority of our samples contained the HPV16 genome in the episomal form (32/39, $82.05 \%)$. The episomal form was present in $73.68 \%$ of SCC cases, suggesting the episomal form is important for HPV16 cervical cancer progression. Although integration-derived transcripts are more stable, episome-derived oncogene transcripts that express E6 and E7 oncoproteins are sufficient to induce centrosome abnormalities and genomic instability in raft cultures $[35,36]$. Using qPCR to differentiate between episomal and mixed forms, a total of 3 discrepancies (integrated form to mixed form) were found when compared to PCR. This is as expected because $\mathrm{qPCR}$ has been shown to be more sensitive than conventional PCR, meaning it is able to detect a low amount of E2 genes in the samples [37]. We then compared the physical state of the viral genome to the expression of E1, and found no significant correlation (Fig. 1b). We speculate that the level of E1 expressed from either the episomal or integrated form is enough to help maintain the viral episome and carcinogenic cells that have already been transformed.

In response to this finding, we further looked for other regulative factors that could influence E1 expression. We explored the methylation of the E2BS positions because, under normal conditions, E2 is able to bind to different binding sites and activate or repress the expression of viral genes, including E1. In this study, the CpG positions near the repressor E2BS were explored. Methylation of these $\mathrm{E} 2 \mathrm{BS}$ positions inhibits $\mathrm{E} 2$ protein binding and mitigates the ability of E2 to regulate the transcription of genes [38]. Our findings indicate that methylation of the E2BS does in fact increase significantly with disease progression (Fig. 3). Oncoprotein overexpression is one of the main causes of cervical carcinogenesis, and it is possible that the hypermethylation of the repressor E2BS is a factor that supports oncoprotein overexpression in cancer patients. As E1 is required to maintain the viral episomal form, it may signify that the presence of the episomal form is important in HPV16-related cervical carcinogenesis. Our data showed that the episomal form of HPV 16 was present in all normal, CIN 1, CIN 2/3, and SCC stages (Table 2). It is possible that the presence of the episomal viral DNA in CIN 2/3 and SCC stages induced hypermethylation of the viral genome compared to normal and CIN 1 samples, but these samples still contained unmethylated-active copies of viral genes, which can be expressed. In addition to the physical state, the viral copy number may also influence methylation and gene expression. The CaSki cell line, which has approximately 600 
copies of integrated HPV16, displayed a mean E2BS methylation of $65.75 \%$ (data from 4 positions showed 56, 70,62 , and $74 \%$ ), while the SiHa cell line containing only 1-2 integrated copies has a mean E2BS methylation of $0.5 \%$ (data from 4 positions showed $1,0,1$, and $0 \%$ ). From these results, we suggested that the viral copy number affects methylation but not E1 expression. Our finding was similar to the E6/E7 expression phenomenon in which the expression level did not depend on the viral copy number [32]. It has been previously noted that SCC samples, which have multiple copies of HPV, are highly methylated [39]. It is possible that our highly methylated samples also have multiple copies of the viral genome. Unfortunately, the viral copy number for each sample was not determined due to limited sample amounts. Overexpression of oncoproteins is the primary cause of HPV-related cancers. Our study shows that the methylation in SCC samples for the repressor E2BS increased more than 3 -fold compared to normal samples. The significant increase in methylation levels of the repressor E2BS, either at each position or combined positions, supports the expression of oncogenic transcripts in transformed epithelium (Fig. 3, 4). In contrast to the early promoter, there was no significant difference in the late promoter (p670) methylation at each position, whereas methylation levels of combined positions were related to disease progression (Fig. 4).

In addition to the expression and regulation of E1, this study also explored additional genetic events, which could possibly be associated with E1 carcinogenesis. A previous study in Europe determined a novel variant form which contained a 63-bp duplication within the E1 ORF. This variant form was further investigated and found to be associated with lower disease progression [20]. Our findings revealed that the 63-bp genomic variant of HPV16, although observed in the Thai population, is most likely rare (4.2\%). All 63-bp positive samples were categorized as CIN 1, supporting the theory that this variant form of E1 is less virulent.

Although we showed an elevation of E1 expression and E2BS methylation with disease progression, a direct correlation remains to be established. Further confirmation in full-length $\mathrm{E} 1 \mathrm{mRNA}$ expression is warranted. A recent study discovered p14, a novel promoter for HPV16 E1. It would be interesting to study the E1 expression pattern of this novel promotor in normal and CIN 1 samples in addition to the CIN 2-positive samples as previously described [40]. In addition, the lack of a proper E1 antibody was a limiting factor in investigating E1 protein expression in different clinical stages. Despite these limiting fac- tors, our results suggest that E1 expression must play some role in carcinogenesis and, therefore, E1 functional assays in vitro are needed.

\section{Conclusion}

A significant increase in E1 transcription, and E2BS and late promoter methylation with regards to disease progression was demonstrated. Our findings suggest that E1 exhibits a correlation with disease progression, much like the well-known oncoproteins E6 and E7. Further studies in a larger number of patients as well as of the functional roles of E1 are warranted. Collectively, we have characterized the expression profile of HPV16 E1 during different stages of cervical cancer disease progression by using ddPCR. We also compared for the first time the expression of HPV16 E1 transcripts in all clinical stages with the methylation level of repressor E2BS and late promoter methylation.

\section{Acknowledgements}

The authors sincerely thank Assoc. Prof. Dr. Somchai Niruthisard (Gynaecology Department, Faculty of Medicine, Chulalongkorn University, Bangkok) for his kindness in reviewing the histological results, Assoc. Prof. Nakarin Kitkumthorn, PhD (Department of Oral Biology, Faculty of Dentistry, Mahidol University, Bangkok) for his advice in the DNA methylation process, and Asst. Prof. Pattarasinee Bhattarakosol, PhD (Department of Mathematics and Computer Science, Faculty of Science, Chulalongkorn University, Bangkok) for helping with the statistical analysis.

This study was supported by the 100th Anniversary Chulalongkorn University Fund for Doctoral Scholarship (2014) and Ratchadapisek Sompoch Endowment Fund, Chulalongkorn University (CU-57-002-HR), and was partially supported by the National Research Council of Thailand (2016).

References

1 Ferlay J, Forman D, Mathers CD, Bray F: Breast and cervical cancer in 187 countries between 1980 and 2010. Lancet 2012;379:13901391.

2 Munoz N, Bosch FX, de Sanjose S, Herrero R, Castellsague X, Shah KV, Snijders PJ, Meijer CJ; International Agency for Research on Cancer Multicenter Cervical Cancer Study Group: Epidemiologic classification of human papillomavirus types associated with cervical cancer. N Engl J Med 2003;348:518-527.

3 Cornet I, Gheit T, Franceschi S, Vignat J, Burk RD, Sylla BS, Tommasino M, Clifford GM, Group IHVS: Human papillomavirus type 16 genetic variants: phylogeny and classification based on E6 and LCR. J Virol 2012;86:68556861. 
-4 Grassmann K, Rapp B, Maschek H, Petry KU, Iftner T: Identification of a differentiationinducible promoter in the E7 open reading frame of human papillomavirus type 16 (HPV-16) in raft cultures of a new cell line containing high copy numbers of episomal HPV-16 DNA. J Virol 1996;70:2339-2349.

5 Bergvall M, Melendy T, Archambault J: The E1 proteins. Virology 2013;445:35-56.

-6 Porter SS, Stepp WH, Stamos JD, McBride AA: Host cell restriction factors that limit transcription and replication of human papillomavirus. Virus Res 2017;231:10-20.

7 Castillo A, Wang L, Koriyama C, Eizuru Y, Jordan K, Akiba S: A systems biology analysis of the changes in gene expression via silencing of HPV-18 E1 expression in HeLa cells. Open Biol 2014;4:130119.

-8 Sakakibara N, Mitra R, McBride AA: The papillomavirus E1 helicase activates a cellular DNA damage response in viral replication foci. J Virol 2011;85:8981-8995.

-9 Bristol ML, Wang X, Smith NW, Son MP, Evans MR, Morgan IM: DNA damage reduces the quality, but not the quantity of human papillomavirus 16 E1 and E2 DNA replication. Viruses 2016;8:E175.

10 Bogovac Z, Lunar MM, Kocjan BJ, Seme K, Jancar N, Poljak M: Prevalence of HPV 16 genomic variant carrying a $63 \mathrm{bp}$ duplicated sequence within the E1 gene in Slovenian women. Acta Dermatovenerol Alp Pannonica Adriat 2011;20:135-139.

11 Peitsaro P, Johansson B, Syrjanen S: Integrated human papillomavirus type 16 is frequently found in cervical cancer precursors as demonstrated by a novel quantitative real-time PCR technique. J Clin Microbiol 2002;40: 886-891.

-12 Nagao S, Yoshinouchi M, Miyagi Y, Hongo A, Kodama J, Itoh S, Kudo T: Rapid and sensitive detection of physical status of human papillomavirus type 16 DNA by quantitative realtime PCR. J Clin Microbiol 2002;40:863-867.

13 Rajeevan MS, Swan DC, Duncan K, Lee DR, Limor JR, Unger ER: Quantitation of site-specific HPV 16 DNA methylation by pyrosequencing. J Virol Methods 2006;138:170-176.

14 Pirami L, Giache V, Becciolini A: Analysis of HPV16, 18, 31, and 35 DNA in pre-invasive and invasive lesions of the uterine cervix. J Clin Pathol 1997;50:600-604.

15 Williams VM, Filippova M, Soto U, Duerksen-Hughes PJ: HPV-DNA integration and carcinogenesis: putative roles for inflammation and oxidative stress. Future Virol 2011;6: $45-57$.

16 Jeon S, Allen-Hoffmann BL, Lambert PF: Integration of human papillomavirus type 16 into the human genome correlates with a selective growth advantage of cells. J Virol 1995; 69:2989-2997.
7 Munger K, Scheffner M, Huibregtse JM, Howley PM: Interactions of HPV E6 and E7 oncoproteins with tumour suppressor gene products. Cancer Surv 1992;12:197-217.

18 Burke JR, Hura GL, Rubin SM: Structures of inactive retinoblastoma protein reveal multiple mechanisms for cell cycle control. Genes Dev 2012;26:1156-1166.

19 Burke JR, Liban TJ, Restrepo T, Lee HW, Rubin SM: Multiple mechanisms for E2F binding inhibition by phosphorylation of the retinoblastoma protein C-terminal domain. J Mol Biol 2014;426:245-255.

20 Sabol I, Matovina M, Gasperov NM, Grce M: Identification of a novel human papillomavirus type $16 \mathrm{E} 1$ gene variant with potentially reduced oncogenicity. J Med Virol 2008;80: 2134-2140.

-21 Walboomers JM, Jacobs MV, Manos MM, Bosch FX, Kummer JA, Shah KV, Snijders PJ, Peto J, Meijer CJ, Munoz N: Human papillomavirus is a necessary cause of invasive cervical cancer worldwide. J Pathol 1999;189: 12-19.

22 Taghizadeh E, Taheri F, Abdolkarimi H, Ghorbani Renani P, Gheibi Hayat SM: Distribution of human papillomavirus genotypes among women in Mashhad, Iran. Intervirology 2017;60:38-42.

23 zur Hausen H: Papillomaviruses and cancer: from basic studies to clinical application. Nat Rev Cancer 2002;2:342-350.

24 Mantovani F, Banks L: The human papillomavirus E6 protein and its contribution to malignant progression. Oncogene 2001;20: 7874-7887.

25 Maufort JP, Shai A, Pitot HC, Lambert PF: A role for HPV16 E5 in cervical carcinogenesis. Cancer Res 2010;70:2924-2931.

26 D’Abramo CM, Archambault J: Small molecule inhibitors of human papillomavirus protein-protein interactions. Open Virol J 2011; 5:80-95.

27 Clower RV, Fisk JC, Melendy T: Papillomavirus $\mathrm{E} 1$ protein binds to and stimulates human topoisomerase I. J Virol 2006;80:1584-1587.

28 Liu JS, Kuo SR, Makhov AM, Cyr DM, Griffith JD, Broker TR, Chow LT: Human Hsp70 and Hsp40 chaperone proteins facilitate human papillomavirus-11 E1 protein binding to the origin and stimulate cell-free DNA replication. J Biol Chem 1998;273:30704-30712.

29 Loo YM, Melendy T: Recruitment of replication protein $\mathrm{A}$ by the papillomavirus $\mathrm{E} 1$ protein and modulation by single-stranded DNA. J Virol 2004;78:1605-1615.

-30 Fradet-Turcotte A, Bergeron-Labrecque F, Moody CA, Lehoux M, Laimins LA, Archambault J: Nuclear accumulation of the papillomavirus E1 helicase blocks S-phase progression and triggers an ATM-dependent DNA damage response. J Virol 2011;85:8996-9012.
1 Schmitt M, Dalstein V, Waterboer T, Clavel C, Gissmann L, Pawlita M: The HPV16 transcriptome in cervical lesions of different grades. Mol Cell Probes 2011;25:260-265.

32 Wang-Johanning F, Lu DW, Wang Y, Johnson MR, Johanning GL: Quantitation of human papillomavirus 16 E6 and E7 DNA and RNA in residual material from ThinPrep $\mathrm{Pa}$ panicolaou tests using real-time polymerase chain reaction analysis. Cancer 2002;94: 2199-2210.

33 Zhang R, He YF, Chen M, Chen CM, Zhu QJ, Lu H, Wei ZH, Li F, Zhang XX, Xu CJ, et al: Diagnosis of 25 genotypes of human papillomaviruses for their physical statuses in cervical precancerous/cancerous lesions: a comparison of E2/E6E7 ratio-based versus multiple E1-L1/E6E7 ratio-based detection techniques. J Transl Med 2014;12:282.

34 Dutta S, Chakraborty C, Dutta AK, Mandal RK, Roychoudhury S, Basu P, Panda CK: Physical and methylation status of human papillomavirus 16 in asymptomatic cervical infections changes with malignant transformation. J Clin Pathol 2015;68:206-211.

35 Duensing S, Duensing A, Crum CP, Munger K: Human papillomavirus type 16 E7 oncoprotein-induced abnormal centrosome synthesis is an early event in the evolving malignant phenotype. Cancer Res 2001;61:23562360.

-36 Jeon S, Lambert PF: Integration of human papillomavirus type 16 DNA into the human genome leads to increased stability of E6 and E7 mRNAs: implications for cervical carcinogenesis. Proc Natl Acad Sci USA 1995;92: 1654-1658.

37 Mackay IM, Arden KE, Nitsche A: Real-time PCR in virology. Nucleic Acids Res 2002;30: 1292-1305.

38 Leung TW, Liu SS, Leung RC, Chu MM, Cheung AN, Ngan HY: HPV 16 E2 binding sites 1 and 2 become more methylated than $\mathrm{E} 2$ binding site 4 during cervical carcinogenesis. J Med Virol 2015;87:1022-1033

39 Chaiwongkot A, Vinokurova S, Pientong C, Ekalaksananan T, Kongyingyoes B, Kleebkaow P, Chumworathayi B, Patarapadungkit N, Reuschenbach M, von Knebel Doeberitz M: Differential methylation of E2 binding sites in episomal and integrated HPV 16 genomes in preinvasive and invasive cervical lesions. Int J Cancer 2013;132:2087-2094.

40 Fedorova M, Vinokurova S, Pavlova L, Komel'kov A, Korolenkova L, Kisseljov F, Kisseljova N: Human papillomavirus types 16 E1 mRNA is transcribed from P14 early promoter in cervical neoplasms. Virology 2016; 488:196-201. 